\title{
DESIGN CENOGRÁFICO: CENOGRAFIA COMO HABILITAÇÃO NOS CURSOS DE DESIGN
}

\author{
Yuri Simon da Silveira \\ Escola de Design - UEMG \\ yuri.Silveira@uemg.br \\ Tatiana Azzi Roizenbruch \\ Escola de Design - UEMG \\ tatiazzi@gmail.com \\ Letícia Braga Corrêa \\ Escola de Design - UEMG \\ leticia.braga.correa@gmail.com
}

Resumo: $O$ ensino do Design tem um caráter multidisciplinar e as áreas de atuação do profissional graduado em design possuem um alcance diversificado. O presente artigo busca investigar a possibilidade de formação de cenógrafos ou designers cênicos a partir de uma nova habilitação específica em uma graduação dos cursos de design. O objetivo desta investigação é apontar as relações entre a cenografia e o design e, a partir de análises curriculares e de referencial teórico do teatro e do design, listar as potencialidades que o designer e sua formação acadêmica podem oferecer ao projeto cenográfico. Tal observação apresentou-se como uma oportunidade de investigação e pesquisa sobre a formação de cenógrafos ou designers cênicos no Brasil.

Palavras-chave: Design, Cenografia, Design Cênico, Processo Projetual, Ensino.

Abstract: The design education has a multidisciplinary approach and the designer can work on a diverse range of areas. This research investigates the possible qualification of scenographers or scenic designers, in Brazil, following a specific graduation or a new habilitation in design courses. The purpose of this research is to point out the relationship between scenography and design and, from curriculum analysis and theoretical theater and design, list the potential that the designer and his academic training can offer the theatrically. This observation was presented as an opportunity to research and research on the formation of set designers and scenic designers in Brazil.

Keywords: design; scenoghaphy; scenic design; education; design process 


\section{INTRODUÇÃO}

O profissional que atue na área de cenografia necessita de uma formação que desenvolva habilidades que o permitam transitar livremente entre as áreas do conhecimento advindas do meio artístico, bem como aquelas de necessidades técnicas e produtivas. Esse hibridismo de conhecimentos possibilita que profissionais, com origens e formações distintas, possam trabalhar em projetos cenográficos. Em muitos países, principalmente nos de língua inglesa, o cenógrafo é denominado como set designer ou scenography design. Tal observação apresentou-se como uma oportunidade de investigação e de pesquisa sobre a formação de cenógrafos ou designers cênicos no Brasil a partir de uma graduação específica ou uma nova habilitação dos cursos de design.

A ideia de uma pesquisa que relacionasse os universos do design e do teatro no Brasil, na qual se estudassem as convergências dessas duas áreas, surgiu após o retorno de um período de estudos na Irlanda. A experiência de graduação sanduiche propiciada aos alunos selecionados da Escola de Design da UEMG, que já possui um histórico de estudos em teatro, pelo programa Ciência Sem Fronteiras possibilitou a realização da matrícula em disciplinas do curso (BA) Performing Arts do Institute of Technology of Sligo ${ }^{1}$. Tal curso oferece diversas competências ou habilitações, tais como atuação (acting), design cênico (theatre design), estudos culturais (cultural studies) e habilidades transferíveis (transferable skills). Os conteúdos das disciplinas relacionadas ao theatre design apresentam grande semelhança aos conteúdos disciplinares relacionados ao ensino de Design.

A ABRACE ${ }^{2}$, quando realizou o Seminário de Design Cênico, definiu essa área de atuação como aquela que trabalha os elementos visuais e sonoros da cena, desenvolvendo projetos nos campos da Cenografia, da Iluminação Cênica, do Figurino, da Maquiagem Cênica, da Sonoplastia, da Direção de Arte e da Arquitetura Cênica. Desse modo, a expertise do designer na área projetual pode então auxiliar o desenvolvimento do espetáculo teatral se o entendermos como um processo que tem como propósito entregar ao público um serviço de entretenimento, a partir de um produto cujo desenvolvimento se originou a partir de um ato projetual.

O objetivo desta investigação é apontar as relações entre a cenografia e o design e, a partir de análises curriculares e de referencial teórico do teatro e do design, listar as potencialidades que o designer e sua formação acadêmica podem oferecer ao projeto cenográfico. Além disso, objetiva sugerir formas de introduzir o conteúdo teórico relacionado ao teatro, a fim de complementar o repertório do profissional do designer. Tal observação apresentou-se como uma oportunidade de investigação e pesquisa sobre a formação de cenógrafos ou designers cênicos no Brasil a partir de uma graduação específica ou de uma nova habilitação dos cursos de design.

Sabemos que, no Brasil, ainda são poucos os profissionais advindos dos cursos de Design. Os projetos de cenografia são, em grande maioria, elaborados por profissionais graduados em cursos de Arquitetura e Artes Visuais. Em muitos casos, principalmente em grupos de teatro, as criações cenográficas são realizadas de maneira intuitiva por profissionais do teatro que têm pouco domínio de áreas técnicas

\footnotetext{
${ }^{1}$ Disponível em: <http://itsligo.ie/courses/ba-hons-in-performing-arts/>. Acesso em: 08 maio 2016.

${ }^{2}$ ABRACE (Associação Brasileira de Pesquisa e Pós Graduação em Artes Cênicas). Disponível em: <http://portalabrace.org/ >. Acesso em: 08 maio 2016.
} 
e projetuais. É importante ressaltar que existe no Brasil formação superior em Cenografia, como o bacharelado específico oferecido pela Unirio ${ }^{3}$, ou uma habilitação dentro de um curso de graduação em Artes Cênicas, como ocorre, por exemplo, com os cursos da Escola de Belas Artes da UFRJ4, ou na Escola de Belas Artes da Universidade de São Paulo ${ }^{5}$. Existe, ainda, a possibilidade de formação em Cenografia em nível de Pós-Graduação em algumas universidades do país.

\section{CENOGRAFIA}

No Design, a concepção da cenografia envolve, também, um importante fator: a interdisciplinaridade. Desse modo, o cenógrafo deve trabalhar juntamente com o dramaturgo do espetáculo, pelo fato de o texto ser a referência inicial de uma concepção cênica. "O espaço teatral é um lugar cênico a ser construído e sem o qual o texto não pode encontrar seu lugar, seu modo concreto de existência" (UBERSFELD, 2005, p.92). Além disso, o trabalho em equipe é fundamental para o desenvolvimento da cena, uma vez que o cenógrafo desenvolve seu projeto com as criações de outros profissionais dessa área, as quais são sempre orientadas pelo diretor/encenador. É importante ressaltar que os a cena surge a partir dos comandos da direção, bem como o espaço em que ela irá se encontrar.

$\mathrm{O}$ ato projetual, imbuído pelos processos de criação e de direção de um espetáculo de artes cênicas, demonstra ser a linha norteadora para a elaboração detalhada do espetáculo. É a partir dele que se estabelecem os critérios para a configuração das equipes de profissionais que atuarão no projeto, assim como as primeiras expressões artísticas adequadas às características necessárias para o início de uma articulação farsesca, que caminhará para a formação da trama e possibilitará que a história seja contada de forma lúdica, criativa, envolvente e surpreendente (SCAPIN JUNIOR, 2011, p 118)

Scapin Junior (2011) considera as questões projetuais, as do trabalho em conjunto ao encenador e as da equipe de criadores do espetáculo como linha condutora da criação cênica. $O$ trabalho interdisciplinar está muito relacionado ao meio de trabalho em que os designers estão inseridos. Para BENEDETTO (2012) o designer cênico, o qual colabora com o diretor e com os outros designers (figurino, luz, maquiagem, adereços, som) para criar um conceito de produção que integra atores, texto e meio ambiente. Pavis (2008) aproxima as questões projetuais - premissa básica para o universo do design - das atividades relacionadas à produção de um espetáculo e relata: "A pluralidade dos métodos, hoje largamente admitida na análise do espetáculo, parece acompanhar um alargamento do paradigma favorito da

\footnotetext{
${ }^{3}$ Bacharelado em Cenografia e Indumentária da Escola de Teatro da UNIRIO. As demandas atuais relativas à atuação do artista em Cenografia e Indumentária exige destes o perfil de artista projetista e pesquisador. Disponível em: <http://www2.unirio.br/unirio/cla/teatro/cenografiaindumentaria>. Acesso em: 08 maio 2016.

${ }^{4}$ Os cursos de Artes Cênicas - Cenografia e Indumentária - da Escola de Belas Artes da UFRJ formam cenógrafos e figurinistas para atuarem na área da arte teatral e em diversas outras áreas artísticas, como: cinema, televisão, publicidade, moda e carnaval. Disponível em: <http://www.eba.ufrj.br/index.php/graduacao/cursos>. Acesso em: 08 maio 2016.

${ }^{5}$ A criação do Curso de Especialização em Cenografia e Figurinos se faz necessária pela carência de escolas especializadas e disciplinas específicas desta área. Acessível no site: http://www.belasartes.br/pos-graduacao/?pagina=cursos\&curso=cenografia.
} 
representação, a visualidade, até os paradigmas da audição, do ritmo e da sinestesia" (PAVIS, 2008, p. 301).

Lupton e Phillips (2008) acreditam no poder agregador dos princípios do design para um reencontro com a forma e com o pensamento visual no processo de criação. Por isso, pode ser importante para esta pesquisa introduzir, com o mesmo propósito de design cênico e linguagem visual, o conceito apresentado por Pavis (2008) de cenografia como "grafia da cena". O termo grafia também é citado por Dondis (2007) como forma de expressão do artista. Podemos, então, defender, na construção cênica, a abrangência de toda a configuração plástica e estética da cena, da visual à sonora, conforme Pavis (2010) recorda, bem como todos os demais estímulos aos quais o espectador pode ser submetido e, também, àqueles estímulos que possam despertar através de nossa memória as sensações que auxiliem na compreensão da cena.

Os conceitos de sintaxe da imagem apresentados por Dondis (2007) orientam sobre a relação entre o espetáculo teatral e o design na medida em que compreendem a mensagem visual contida na linguagem da cena, as técnicas envolvidas e as funções práticas, simbólicas, estéticas e poéticas do espetáculo teatral. Também para Flusser (2007), o olhar observa e cria significações para a imagem, visto que estabelece um rumo para nossas percepções. Scapin Junior (2001) relaciona, então, o pensamento de Flusser ao "fazer teatral", afirmando que podemos estabelecer relações significativas entre o olhar para as artes cênicas a partir do pensamento do designer, já que, para o espectador, o olhar tende a eleger elementos preferenciais na cena, centrais ao entendimento do espetáculo, transmissores de informações e portadores de significados. Assim, é possível fazer alusão ao olhar da plateia, que identifica ou percebe os significados que foram propostos pelos criadores do espetáculo ao traduzirem, por meio da plasticidade da cena, as mensagens embutidas no texto, estabelecendo entre o emissor e o receptor da mensagem uma cumplicidade.

Um projeto cenográfico exige do profissional responsável conhecimentos ou expertises que são desenvolvidas e transmitidas em cursos de design. "O Designer em geral usa sentidos, formas, cores, composições, com os quais constitui imagens, espaços para expressar criativamente um diálogo com o mundo, o que demanda um conhecimento desse conjunto." (COHEN, 2007, p. 55). Além das características visuais estéticas, o caráter simbólico atribuído aos elementos cenográficos desenvolvidos e acrescentado à cena tem extrema importância no projeto de um espetáculo.

Para Roubine (1998), o espetáculo teatral é composto por uma visualidade cênica unificada que tem origem no trabalho conjunto de seus criadores sob a orientação do encenador.

\footnotetext{
Mas como fazer do espetáculo essa unicidade estética e orgânica? Contrariamente às outras formas de arte, a encenação aparece em primeiro lugar como uma justaposição ou imbricação de elementos autônomos: cenário e figurino, iluminação e música, trabalho de ator. [...] Por conseguinte, uma vontade soberana deve impor-se aos diversos técnicos do espetáculo. Essa vontade conferirá à encenação a unidade orgânica e estética que lhe falta, mas também a originalidade que resulta de uma intenção criadora (ROUBINE, 1998, p. 42)
}

BENEDETTO (2012) ressalta a importância da cenografia para o espetáculo de teatro como forma de comunicação direta com o público, pois, em muitas vezes, ela é o primeiro aspecto observado pelo público ao entrar no teatro. Esse primeiro contato com a montagem que, além de configurar o estilo utilizado, vai transmitir para o 
espectador a atmosfera e o conceito que a produção pretende passar com o espetáculo, define, também, o tempo e o lugar no espaço da cena. Ainda para Benedetto (2012), os designers cênicos contemporâneos não se limitam a reproduzir as configurações como se fossem reais, mas, deliberadamente, escolhem os elementos para moldar a impressão de uma audiência dos mundos representados dentro da peça.

Em RATTO (1999), percebe-se que, tanto para o designer quanto para o cenógrafo, a expressão artística e o conhecimento histórico devem vir acompanhados de habilidade técnica, não apenas para executar uma peça única, mas para sistematizar um produto que, embora mais efêmero que uma edificação permanente, será remontado muitas vezes e, em muitos casos, em outros espaços teatrais.

Nesse sentido o cenógrafo é um homem da arte, não necessariamente um artista. E é nisso, parece-me, que reside a sua grande força poética, porque, à diferença daqueles pedreiros, artesãos e ourives, seu produto é aleatório e circunstancial, indispensável e inútil ao mesmo tempo (RATTO, 1999, p.60)

Os processos de significação e de linguagem da semiótica desempenham papel fundamental na comunicação que se estabelece entre a cena e o espectador. "Os signos não só servem para a caracterização dos personagens e do espaço, mas também tem a função de participar da ação dramática." (OTAKAR, apud, IGARDEN, 1977, p.17). Embora possam ser desenvolvidos por outros profissionais em um mesmo espetáculo, o figurino, a maquiagem e os adereços também fazem parte da composição do universo cenográfico, de modo que cada detalhe carrega em si significados que podem sugerir interpretações e estabelecer a comunicação desejada pela encenação do espetáculo.

Os objetos que desempenham em cena o papel de signo adquirem nisso determinados traços, qualidades e marcas que não possuem na vida real. As coisas, assim como o próprio ator, renascem, no teatro, diferentes. [...] 0 problema da percepção e interpretação dos signos merece ser analisado com os métodos da teoria da informação. Onde há um sistema de signos, deve existir um código. Os códigos dos signos empregados no teatro nos são proporcionados pela experiência individual ou social, a instrução, a cultura literária e artística (IGARDEN,1977, p. 18 e 79)

\section{DESIGN - PROJETO}

O trabalho projetual do designer pode ser respaldado pelo pensamento de Bonsiepe (1997), que, ao reinterpretar as ações do design, elenca algumas características pertinentes que servem a ambos os campos de atuação, atribuindo ao design a responsabilidade pela construção da relação entre produto/serviço e consumidor.

(1) Design é um domínio que pode se manifestar em qualquer área do conhecimento e práxis humana. (2) O design é orientado para o futuro. (3) 0 design está relacionado à inovação. $O$ ato projetual introduz algo novo no mundo. (4) O design está ligado ao corpo e ao espaço, particularmente ao espaço retinal, porém não se limitando a ele. (5) Design visa à ação efetiva. (6) Design está linguisticamente ancorado no campo dos juízos. (7) Design se orienta à interação entre usuário e artefato. O domínio do design é o domínio da interface (BONSIEPE,1997, p. 15). 
Os conceitos apresentados por Bonsiepe (1997) deixam extremamente claro o caráter abrangente do termo design e de seu campo de atuação, trazendo para o universo do design uma visão pragmática, de interface e interação que nos remetem, novamente, a questões de interdisciplinaridade. $O$ design não se esgota em si mesmo, visto que necessita interagir com outras áreas do conhecimento, entendendo as necessidades de um mundo complexo e multicultural e podendo oferecer os melhores resultados em relação às necessidades contemporâneas.

O campo de atuação que poderíamos denominar Design Cenográfico ou Design Cênico pode ser uma possibilidade para os profissionais de design a partir do conceito de sua formação multidisciplinar. "Aplicar o termo design na cena implica um processo criativo, incluindo questões de estilo, afirmações poéticas, e pode sugerir inventividade." (TUDELLA, 2012, p. 2). Em muitos países, principalmente nos de língua inglesa, o cenógrafo é denominado como scenic designer.

\begin{abstract}
Em inglês, a palavra design funciona como substantivo e também como verbo (circunstância que caracteriza muito bem o espírito da língua inglesa). Como substantivo significa, entre outras coisas, propósito, plano, intenção, meta, forma, estrutura básica. [...] Na situação de verbo - to design significa, entre outras coisas, tramar algo, simular, projetar, esquematizar, configurar, proceder de modo estratégico (FLUSSER, 2008, p. 181).
\end{abstract}

Se compreendermos o espetáculo teatral como um processo que tem como propósito entregar ao público um serviço de entretenimento que parte de um ato projetual que desenvolve um produto, a expertise do designer pode ser necessária.

No artigo "Competências para o design na sociedade contemporânea", Krucken (2008) aborda o caráter mediador do design e o conceito proposto mais recentemente pelo $\operatorname{ICSID}^{6}$ (2005).

Design é uma atividade criativa que tem como objetivo estabelecer as
múltiplas qualidades dos objetos, processos, serviços e seus sistemas em
todo seu ciclo de vida. Portanto, o design é um fator central para a
humanização inovadora das tecnologias e um fator crucial para a troca
econômica e cultural (ICSID 2005, apud KRUCKEN, 2008, p.25)

A presença do designer em diversos ramos de atividade tem se tornado cada vez mais frequente. Existem possibilidades de atuação em diversos segmentos para o designer. Krucken menciona que "de fato, é a percepção sistêmica que caracteriza e estimula a atuação do design na contemporaneidade" (KRUCKEN, 2008, p. 26). Essa afirmação pode gerar uma interpretação sobre as várias possibilidades de atuação em diversos segmentos para o designer.

Nesse contexto, a montagem de um espetáculo teatral pode ser considerada um sistema complexo, que abrange diversas áreas de conhecimentos, tais como planejamento de projeto, processo de criação, contextualização histórica, elementos de percepção, referências estéticas, características formais e simbólicas. Todas essas áreas permeiam tanto a atividade teatral quanto a do designer. Por isso, essa percepção sistêmica pode possibilitar que o designer também atue em todas as fases do processo de montagem de um espetáculo, organizando cada uma das etapas de

\footnotetext{
${ }^{6} \mathrm{O}$ Icsid (International Council of Societies of Industrial Design) é uma organização não governamental para proteção e promoção dos interesses da profissão do Design Industrial. Disponível em/:

<http://www.icsid.org/about/about.htm>.Acesso em: 08 maio 2016.
} 
produção, das escolhas de materiais, levantamentos de custos, viabilidade de realização, adequação de projetos até os estudos de ergonomia e usabilidade. "O processo projetual é ou deveria ser um processo de pensamento disciplinado, se caracteriza pela grande agilidade de passar de um problema parcial para outro problema parcial, avaliando as implicações de um sobre o outro." (BONSIEPE, 1984, p.10).

Sobre isso, Krucken (2008) salienta a necessidade de os designers se posicionarem no contexto em que o desenvolvimento de projetos se caracteriza como sistemas (incorporando produtos, serviços e comunicação), articulando relações transversais de conhecimento, buscando ferramentas que ampliem seu espaço de interação e que nos fazem repensar as formas de intervenção sistêmica do design na sociedade a partir da cultura e da prática do projeto. Nessa linha de pensamento, Manzini (2008) nos permite refletir sobre o ato de projetar, o qual amplia o espaço de atuação pela transversalidade que o design faz com diversas outras áreas. Assim, podemos considerar que cabe ao designer, também, o papel de leitor e tradutor dos desejos, anseios e necessidades do consumidor, tendo como premissa sua relação com o cotidiano em diversas instâncias, tais como o consumo de bens e serviços, lazer e entretenimento.

O pensamento de design tem sua natureza nos processos de integração de situações e dados para solução de problemas. O designer atua em projetos com bastante mobilidade pela sua "capacidade intuitiva, por reconhecer padrões, desenvolver ideias que tenham um significado emocional além do funcional, expressar-se em mídias além de palavras ou símbolos." (BROWN, 2010, p.4). A combinação de métodos e processos que o designer aplica em projetos tem um caráter sistêmico e se diferencia por centrar-se, sobretudo, no usuário, que especificamente no teatro, não seria necessariamente apenas espectador, mas, também, ator que utiliza os elementos cenográficos projetados para o espaço cênico e todos os demais envolvidos na ação dramática, direta ou indiretamente.

\section{A FORMAÇÃO EM DESIGN}

A formação em Design possui características pedagógicas próprias e conhecimentos que transitam pelos campos da arte, da comunicação, da gestão de projetos, da ciência da informação e da tecnologia. Esses conhecimentos proporcionam competências amplas e sistêmicas que estão em transformação desde as experiências pioneiras da Bauhaus ${ }^{7}$. O contexto da pesquisa remete exatamente a essa pluralidade de possibilidades de atuação do designer e às diversas correspondências entre ambos os segmentos.

A partir do estudo de caso realizado pelo projeto pedagógico ${ }^{8}$ dos cursos de design da Escola de Design da Universidade do Estado de Minas Gerais, o designer graduado adquiriu conhecimentos que contribuem com o seu trabalho de projetar de

\footnotetext{
${ }^{7}$ A Escola Bauhaus original foi fundada em 1919 em Weimar na Alemanha por Walter Gropius como um novo modelo de Escola de Design.Disponível em: < http://www.bauhaus-dessau.de/the-bauhausbuilding-by-walter-gropius.html >. Acesso em: 08 maio 2016.

${ }^{8} \mathrm{O}$ projeto pedagógico da Escola de Design pode ser consultado na Coordenação e Chefias de Departamento da Escola de Design - UEMG.
} 
forma ampla. Em sua formação acadêmica multidisciplinar ${ }^{9}$, Estudos sobre comunicação visual e métodos da teoria da informação e semiótica fazem parte da grade curricular, além dos princípios de composição, elementos de percepção, análise formal, linguagem visual e teoria das cores, que são ferramentas fundamentais na criação e na composição cenográfica.

Nos cursos de design, existem, ainda, disciplinas que auxiliam diretamente no ato de desenhar e projetar graficamente um cenário. A expressão gráfica, o desenho técnico e a representação tridimensional possibilitam a materialização da concepção visual do projeto de cenografia. Os repertórios teóricos adquiridos em disciplinas de história da arte e do design habilitam o profissional a contextualizar e embasar sua pesquisa simbólica de forma coerente, bem como realizar as melhores escolhas dos elementos visuais que farão parte da cena.

As práticas de projetos de design, os conhecimentos obtidos em sua formação e sua capacidade de sistematizar o diálogo com outros profissionais ampliam as possibilidades de atuação do designer em áreas como a cenografia.

Saber que o desenvolvimento de determinado conjunto de noções e
competências capacita o designer a olhar o mundo de uma maneira
particular, com o 'filtro' do design, contribui para o autoconhecimento deste
profissional e possibilita visão mais abrangente do seu campo de atuação
(SIQUEIRA, 2012, p. 23).

Para o profissional graduado em design não existe apenas um único espaço reservado no mercado de trabalho, mas inúmeros. O lugar de trabalho do designer é aquele em que no qual há a procura por um profissional que articule meios, interfaces e que solucione os problemas de comunicação e entendimento entre um produto/serviço e seu público.

Para exemplificar melhor os argumentos apontados anteriormente, foram escolhidas três disciplinas comuns aos três cursos de design da Escola de DesignUEMG, a saber, (i) design de produto, (ii) design gráfico e (iii) design de ambientes. As disciplinas pertencem aos dois primeiros anos da formação do designer, nos quais o conteúdo possui caráter menos específico quanto à pratica de projeto e mais relacionado aos fundamentos do design, técnicas e ferramentas do processo. São elas, (i) Psicologia Percepção e Forma; (ii) Expressão Gráfica e (iii) Representação Técnica e Tridimensional.

Um projeto cenográfico inclui aspectos objetivos e subjetivos, os quais se relacionam com o texto dramatúrgico: o desenvolvimento dos personagens, as escolhas de encenação e composição de cena a partir do texto. Há, também, aspectos mais subjetivos que são presentes nos subtextos e nas entrelinhas do espetáculo. Partindo da análise das ementas e dos objetivos das disciplinas dos cursos de Design da Escola de Design - UEMG, fizemos uma seleção de requisitos que se adéquam à necessidade de um cenógrafo - que a partir de agora chamaremos de "designer cênico" - em sua atuação em um projeto cenográfico.

Para conceber criativamente um cenário, um designer cênico deverá ter conhecimentos fundamentados na morfologia e na psicologia da percepção. Desse modo, deve ser capaz de, no plano pictórico, desenvolver sua percepção dos

\footnotetext{
${ }^{9} \mathrm{O}$ conteúdos das disciplinas e grade currícular dos cursos de Design podem ser consultadas no site da Escola de Design da Universidade do Estado de Minas Gerais. Disponível em: <http://ed.uemg.br/cursos/graduacao/design-produto>. Acesso em: 08 maio 2016.
} 
elementos visuais e compreensão do espaço tridimensional. Nesse contexto, deve adotar critérios de organização da forma no espaço e demonstrar capacidade interpretativa das cores através da arte. A cenografia de um espetáculo ganha em qualidade e funcionalidade quando seu profissional tem senso de aplicabilidade das formas, cores, símbolos e conceitos históricos e perceptivos. Os objetivos citados anteriormente estão presentes no conteúdo da disciplina de Psicologia, Percepção e Forma I, II, III, e IV, que é ministrada em quatro semestres.

Ao desenvolver elementos visuais (cenário, figurino, maquiagem etc.) para um espetáculo, o profissional deve ser capaz de representar graficamente através do desenho suas ideias, evidenciando o volume, a proporção e a perspectiva. Além disso, deve desenvolver sua capacidade de leitura e interpretação crítica de imagens para apropriar-se de técnicas aprendidas a fim de apresentar seus conceitos e processos de forma coerente, esquemática e sintética. As disciplinas de expressão gráfica propõem conteúdos programáticos que contemplam esses objetivos, apresentando atividades que envolvem a experimentação e o desenvolvimento do aluno para explorar as diversas técnicas de expressão.

Durante a transição da etapa de ideação e geração de alternativas para a etapa de síntese e desenvolvimento da solução final, um designer cênico precisa registrar suas soluções da forma mais clara e técnica possível. O projeto conta sempre com uma equipe de produção e montagem que precisa de documentos com medidas e informações exatas para a execução do projeto. Para isso, é importante que o profissional compreenda a linguagem técnica e desenvolva seu raciocínio espacial, geométrico e técnico. Além disso, é preciso que tenha capacidade de representar bidimensional e tridimensionalmente as formas e funções, evidenciando dimensões, posições relativas, bem como o aspecto e o material relacionado ao projeto. Esse profissional precisa ser capaz de utilizar e interpretar os princípios e normas (ABNT) do desenho arquitetônico, bem como a representação de espaços. Sua capacidade de finalizar modelos digitalmente e acabamentos, manuais ou digitais, é importante para a apresentação da solução escolhida para o projeto. Esse conteúdo é abordado nas disciplinas de Representação Técnica e Tridimensional, sendo que esta ultima ainda possui um semestre no qual os princípios e fundamentos básicos da cenografia são aprofundados, com a produção de um projeto de cenário como trabalho final da disciplina.

A formação multidisciplinar do designer e sua relação com inovações socioculturais e tecnológicas, com caráter mediador e uma perspectiva mais abrangente e sistêmica, podem possibilitar a ampliação do campo de atuação desse profissional, como aquela requisitada, também, pelo campo das artes cênicas. Assim, como podemos perceber, por possuir áreas de conhecimento e possibilidades de atuação diversificadas, para o profissional graduado em design não existe apenas um único espaço reservado no mercado de trabalho, mas inúmeros. Onde haja a necessidade de um profissional que articule meios, interfaces e que solucione os problemas de comunicação e entendimento entre um produto/serviço e seu público, este é o local de trabalho do designer. 


\section{REFERÊNCIAS}

ABRACE - ASSOCIAÇÃO BRASILEIRA DE PESQUISA E PÓS-GRADUAÇÃO EM ARTES

CÊNICAS. Disponível em: <http://portalabrace.org/>. Acesso em: 02 nov. 2015.

BAUHAUS - BAUHAUS DESSAU. Disponível em: <http://www.bauhaus-dessau.de/thebauhaus-building-by-walter-gropius.html>. Acesso em: 02 nov. 2015.

BENEDETTO, Stephen Di. An Introduction to Theatre Design. Abingdon: Routledge. 2012.

BONSIEPE, Guy. Metodologia Experimental: design industrial. Brasília: CNPq/Coordenação Editorial, 1984.

. Design do Material ao Digital. Florianópolis: Sebrae-SC/Fiesc. 1997.

BROWN, Tim. Design Thinking: uma metodologia ponderosa para decretar o fim das velhas ideias. Rio de Janeiro: Elsevier, 2010.

COHEN, Mirian Aby. Cenografia Brasileira Século XXI: diálogos possíveis entre a prática e o ensino. Dissertação de Mestrado, Área de Concentração: Artes Cênicas - Escola de Comunicação e Artes da Universidade de São Paulo, São Paulo: 2007.

DONDIS, Donis A. Sintaxe da Linguagem Visual. 4 ed. São Paulo: Martins Fontes, 2007.

FLUSSER, Vilém. 0 mundo codificado: por uma filosofia do design e da comunicação.

São Paulo: Cosac Naif, 2008.

INGARDEN, Roman, BOGATYREV, Petr, HONZL, Jindrich e KOWZAN, Tadeusz. O Signo Teatral: a semiologia aplicada à arte dramática. Editora Globo, Porto Alegre, 1977.

LUPTON, Ellen; PHILLIPS, Jennifer Cole. Novos Fundamentos do Design. São Paulo: Cosac Naify, 2008.

MANZINI, Ezio. Design para inovação social e sustentabilidade: comunidades criativas, organizações colaborativas e novas redes projetuais. Rio de Janeiro: Editora e-papers, 2008

MORAES, Dijon de (Org.). KRUCKEN, Lia. (Org.) Design e multiculturalismo. Cadernos Avançados em Design. Belo Horizonte: EdUEMG. 2008.

PAVIS, Patrice. Dicionário de teatro. São Paulo: Perspectiva, 2008

A análise dos espetáculos. São Paulo: Perspectiva, 2010

RATTO, Gianni. Antitratado de Cenografia: variações do mesmo tema. São Paulo:

Editora SENAC, 1999.

ROUBINE, Jean-Jacques, A linguagem da encenação teatral: 1880-1980. Rio de Janeiro: Ed. Jorge Zahar, 1998

SACHS, Ignacy. 2002. Caminhos para do Desenvolvimento Sustentável. Rio de Janeiro: Garamond.

SCAPYN JUNIOR, Ary. O Design Cênico do Circo: um olhar para o processo projetual. Dissertação de Mestrado - Área de Concentração: Design - Universidade Anhembi Morumbi, São Paulo, 2011 
SIQUEIRA, Heitor Piffer. Aspectos próprios ao universo de noções e competências do design identificáveis, eventualmente, na atuação de indivíduos formados nesta área no desempenho de outras atividades profissionais. Dissertação Mestrado - Área de Concentração: Design e Arquitetura - FAUUSP. São Paulo, 2012.

UNIVERSIDADE DO ESTADO DE MINAS GERAIS, Escola de Design. Projeto pedagógico: Curso Design de Produto. Belo Horizonte: UEMG, 2003, $61 \mathrm{f}$.

UBERSFELD, Anne. Para ler o teatro. São Paulo: Perspectiva, 2005.

YIN, Robert K. 2007. Estudo de Caso: planejamento e métodos. 2 ed, Porto Alegre:

Editora FGV. 